\title{
ASO Visual Abstract: Failure to Thrive Following Cytoreduction and Hyperthermic Intraperitoneal Chemotherapy: Causes and Consequences
}

\section{Caroline J. Rieser, MD, MS ${ }^{1,2}$ [D , Jurgis Alvikas, MD ${ }^{1}$, Heather Phelos, MPH ${ }^{3}$, Lauren B. Hall, MSc ${ }^{1}$,} Amer H. Zureikat, $\mathbf{M D}^{1}$, Andrew Lee, MD ${ }^{1}$, Melanie Ongchin, $\mathbf{M D}^{1}$, Matthew P. Holtzman, $\mathbf{M D}^{1}$, James F. Pingpank, MD ${ }^{1}$, David L. Bartlett, $\mathrm{MD}^{4}$, and M. Haroon A. Choudry, MD ${ }^{1}$

${ }^{1}$ Division of Surgical Oncology, Koch Regional Perfusion Center, University of Pittsburgh, Pittsburgh, PA; ${ }^{2}$ UPMC Cancer Pavilion, Pittsburgh, PA; ${ }^{3}$ Department of Surgery, University of Pittsburgh, Pittsburgh, PA; ${ }^{4}$ AHN Cancer Institute, Allegheny Health Network, Pittsburgh, PA

Failure to thrive (FTT) is common after cytoreductive surgery/hyperthermic intraperitoneal chemotherapy (CRS/ HIPEC). It is associated with ostomy, venous thromboembolism events, discharge to a skilled nursing facility, preoperative chemotherapy, older age, and female sex. FTT readmission within 90 days of discharge after CRS/ HIPEC is associated with worse survival (hazard ratio $1.58, p<0.01$ ) [https://doi.org/10.1245/s10434-021-11100-z].

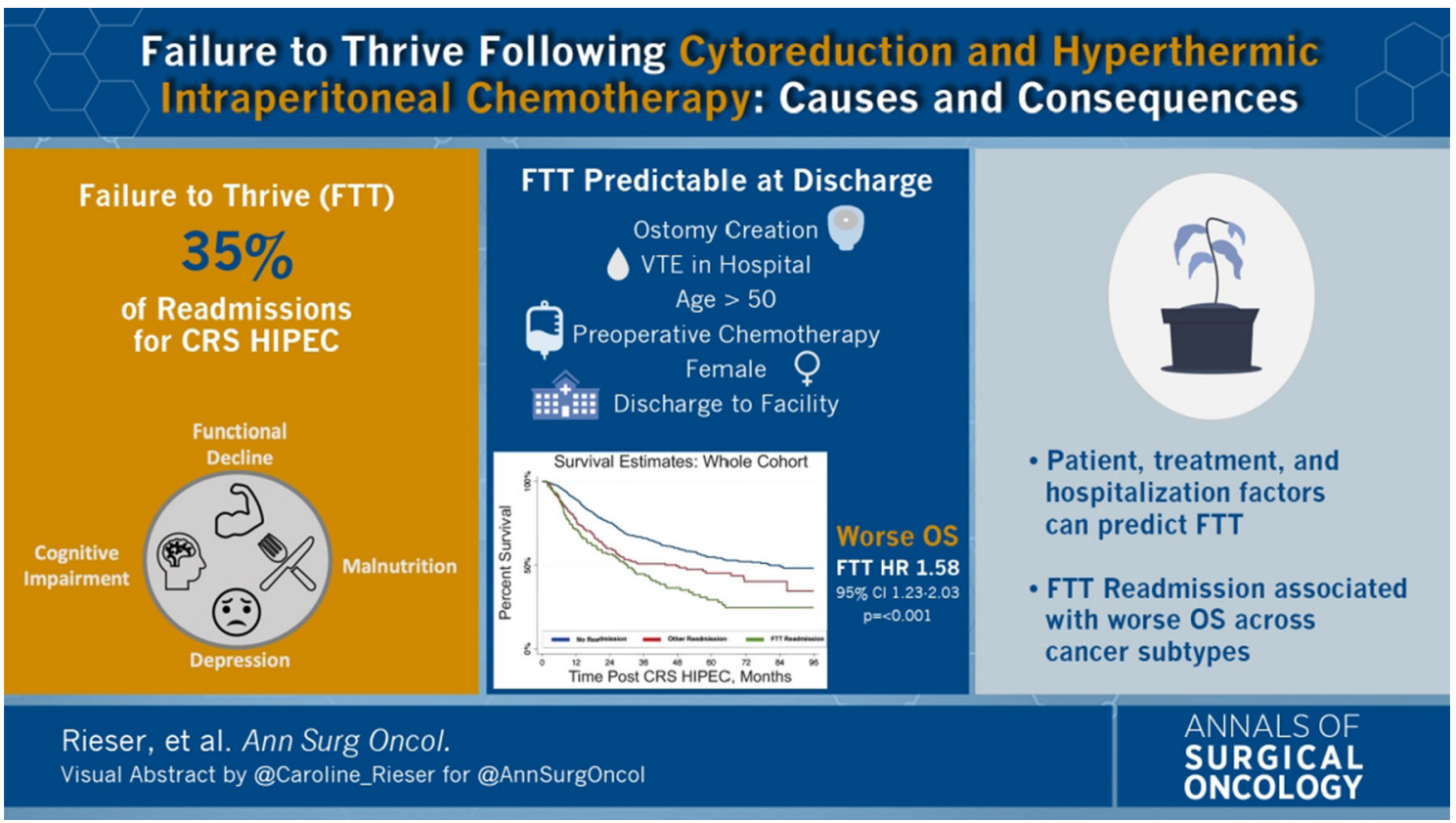

(C) Society of Surgical Oncology 2022

C. J. Rieser, MD, MS

e-mail: riesercj2@upmc.edu

DISCLOSURES Caroline J. Rieser, Jurgis Alvikas, Heather Phelos, Lauren B. Hall, Amer H. Zureikat, Andrew Lee, Melanie Ongchin, Matthew P. Holtzman, James F. Pingpank, David L. Bartlett, and M. Haroon A. Choudry have no financial relationships to disclose..

Publisher's Note Springer Nature remains neutral with regard to jurisdictional claims in published maps and institutional affiliations. 